\section{HANNAH ARENDT Y LOS DERECHOS HUMANOS}

\author{
Reyes Mate \\ Instituto de Filosofía - CCHS/CSIC
}

\begin{abstract}
The Declaration of the Rights of Man and Citizen represents a historical hallmark and a political referent. Hannah Arendt is a lucid observer of the link that is established between the principle of the rights of man and citizenship, the belonging to a political community; but this is based on being born in a territory. For those who cannot brandish this belonging or who have been disposessed of it, these rights are an abstraction without any validity.
\end{abstract}

KEY WORDS: Arendt; Agamben; human rights; citizenship; nationality.

\section{1}

Los derechos humanos son un logro histórico por la sencilla razón de que ahí se mide la dignidad del hombre por el nacimiento y no por la cuna. Lo que pasa es que ese hito histórico arrastra un grave problema: si resulta que el hombre es el legislador y por tanto la instancia superior de la ley, ¿cómo obligarle a cumplirla si no quiere? ¿A qué instancia acudir si ya no reconocemos la autoridad de Dios o de la naturaleza?

La sospecha de que el hombre bien pudiera no respetar los derechos (y por tanto no cumplir los deberes) a los que se debe por nacimiento, por ser hombre, está más que fundada. Hannah Arendt no necesita recurrir a los periódicos para ilustrar la sospecha. Le basta recorrer la Declaración de los derechos del hombre y del ciudadano de 1789. El artículo primero remite los susodichos derechos al hecho de nacer, mientras que el segundo, al hecho de ser ciudadano.

No es lo mismo. Si remitimos los derechos del hombre al hecho de ser hombre, hay que respetarlos siempre; si los supeditamos al hecho de ser ciudadano, sólo serán respetados cuando la nación que nos da la ciudadanía así lo quiera. ¿Qué pasará entonces con los des-naturalizados o des-nacionalizados? Tomemos en cuenta que las variantes

\section{HANNAH ARENDT AND THE HUMAN RIGHTS}

RESUMEN: La Declaración de los derechos de Hombre y de Ciudadano representa un hito histórico y un referente politico. Hannah Arendt es una lúcida observadora de la vinculación que se establece desde el principio de los derechos del hombre a la ciudadanía, a la pertenencia a la comunidad política, pero ésta se basa en el nacimiento en un territorio. Para quienes no pueden esgrimir esa pertenencia o hayan sido desposeídos de ella, esos derechos son una abstracción carente de vigencia.

PALABRAS CLAVE: Arendt; Agamben; derechos humanos; ciudadanía; nacionalidad.

de unos y otros son múltiples: refugiados, sin-papeles, retenidos en zonas internacionales de aeropuertos...

Arendt anota que desde el primer momento se vinculó derechos del hombre a ciudadanía, de ahí la querencia a identificar al hombre, sujeto de derechos, con el pueblo y no con el individuo. Esto lo sabían la legión de apátridas de entreguerras, por eso reclamaban papeles. Sabian por experiencia que de poco valía la condición humana si no tenías papeles. La misma actitud encontramos entre muchos supervivientes de la II Guerra Mundial. Pobre del que no tuviera más capital que su dignidad humana. Para los Estados la exigencia del reconocimiento de unos derechos humanos, basados en la mera dignidad, era, como decía Reagan, "una carta a los Reyes Magos".

Ese era el primer problema, pero había otro: ponerse de acuerdo sobre sus contenidos. En la Declaración de 1789 había una lista, así que podemos decir que esa lista era su contenido. Si alquien negara algunos de esos derechos, podríamos decir que niegan los derechos del hombre. Pero de poco valen esos derechos concretos si no existe algo así como un derecho a los derechos, de suerte que si uno $u$ otro es violado queda la posibilidad de exigir responsabilidades porque se reconoce, en cualquier caso, la figura de un sujeto de derechos. Para explicar esto, Arendt ${ }^{1}$ recurría al ejemplo de lo que pasaba en su tiempo. Ocurría, en efec- 
to, que si uno perdía su nacionalidad, perdia la pertenencia a la especie humana; si uno quedaba sin hogar, perdía el derecho a tener hogar; cuando uno perdía la protección de su gobierno, quedaba incapacitado para poder cobijarse bajo cualquier otro. Esto explica que el delincuente tuviera un status jurídico muy superior al del apátrida, por buena gente que fuera. Al delincuente se le reconocian derechos y deberes, por eso se le sancionaba. El apátrida, por el contrario, vivía en un Guántanamo avant la lettre.

Como la idea de tener derecho a derechos procede de la pertenencia a una comunidad, conviene revisar la idea de unos derechos humanos basados en la naturaleza. Los derechos humanos no son derechos naturales, no son un derivado de la naturaleza humana porque esa naturaleza no es de fiar. No podemos confiar en que ella garantice el derecho a los derechos porque el hombre hace de su naturaleza lo que quiere, para bien y para mal. ¿Podríamos recurrir entonces a una figura como La Humanidad para garantizar esos derechos a los que tenemos derecho? Si estamos pensando en algo así como "un gobierno mundial", lo que hay que decir es que de momento estamos lejos pues no conocemos ni reconocemos otra forma de universalidad o mundialidad que la del entendimiento entre Estados. Volvemos al Estado.

El pensador conservador Edmond Burke se oponía a toda teoria de los derechos humanos, planteando con gran realismo que sólo se reconocieran los derechos que emanaran de "dentro de la nación". Tenía muy claro lo que luego vería Arendt, a saber, que si no eres miembro de una nación, no hay derechos que valgan.

Lo importante es ser miembro de una comunidad, de ahí la pregunta: ¿Qué es lo que nos hace ser miembro de una nación? La respuesta que da: "Es el resultado del trabajo común, producto del artificio humano". La comunidad es la esfera iluminada por la ley de la igualdad, una igualdad que no es dada sino construida, conquistada. "Nuestra vida política", dice Arendt (1987, 437), "descansa en la persuasión de que podemos producir la igualdad a través de la organización porque el hombre puede actuar en un mundo común, cambiarlo, construirlo, junto con sus iguales y sólo con sus iguales".
¿Qué se deduce de todo esto? Que es mucho más importante el nacimiento en un territorio determinado que la condición o dignidad humana.

El lugar de Dios en la fundamentación de la política y de la moral, ha sido ocupado por una instancia terrenal que es de hecho un triunvirato: Estado-nacimiento-territorio. Es el Estado-Nación. Esto significa que la comunidad política moderna no se basa en la voluntad de sus miembros, ni en una disposición a crear el bien común, sino en el nacimiento en un territorio. Al Estado sólo le interesa el cuerpo, la nuda vida, no la inteligencia ni la voluntad de los suyos. ¿Por qué es tan importante "la sangre y la tierra"? "Porque", dice Arendt, "el poder, el Estado nacional, no soporta elementos que alteren la cohesión grupal". Tiene miedo de las diferencias, producidas por el uso de la libertad, y más aún, de las diferencias étnicas, que no se pueden alterar ni manipular (Arendt, 1987,436). Por eso las combate, remitiéndolas a la vida privada o destruyéndolas.

Mientras esa tríada funciona, no hay problemas, es decir, mientras los habitantes del territorio son de los allí nacidos, el Estado los representa. Pero ¿qué pasa cuándo se cuartea esa representación sea porque hay muchos no-nacidos en ese territorio, sea porque muchos de los allí nacidos no se identifican con esa representación nacional? Pues que el Estado entra en crisis y para resolver el problema de la representación crea una figura, un lugar extraño, que es interior y exterior al Estado: el campo de concentración. Los ahí deportados viven en estado de excepción, en el sentido de que sus derechos son suspendidos, sin que eso, por otro lado, signifique que queden liberados. Nada de eso: están a merced de la voluntad del Estado, sin leyes ni derechos que medien entre el poder y los individuos.

A ese extraño lugar están destinados los sin-papeles y los des-nacionalizados.

\section{3}

Deberíamos hablar con más rigor de los derechos humanos, es decir, deberíamos dejar bien claro que sólo podemos hablar como hablamos de ellos (dando por descontado que 
"existen" los derechos humanos), si cerramos los ojos a la realidad de in-humanidad en la que vive el hombre.

Los derechos humanos, según al artículo primero de la Declaración de 1789, son derechos que se reconocen al hombre, a la condición humana, independientemente de su condición social. Si miramos a nuestro alrededor y vemos lo que ocurre, observamos que lo que importa del hombre no es su condición social, ni siquiera su condición humana, sino su condición animal: la sangre y la tierra.

En esta deriva de lo social a lo animal se encuentra el punto de encuentro y de desencuentro entre Arendt y Agamben. El pensador italiano acepta, como punto de partida, la idea arendtiana de que la invocación del ser humano no es ninguna garantía de que se le reconozcan los derechos humanos. Como desde el principio se ha ligado Derechos Humanos y ciudadanía, Arendt se pronuncia descaradamente a favor de los papeles, es decir, a que se le reconozca al ser humano por el Estado de turno los derechos que ellos reconocen a sus ciudadanos. Lo que señala Agamben es que tengamos cuidado con la Nación, que viene de nacimiento y se sustenta en la sangre y en la tierra. En la Nación el nacimiento se convierte en elemento político determinante. Es la política como biopolítica: para el Estado el hombre es un cuerpo que proteger, de ahí que lo que fundamente la soberanía sea el cuidado del cuerpo.

\section{4}

Eso nos lleva afirmar que los famosos derechos humanos son una abstración, en el preciso sentido de que sólo podemos hablar de su existencia, si hacemos abstracción de la situación real en que vive el hombre en la sociedad, es decir, si declaramos teóricamente irrelevante el hecho de que el hombre en la realidad no sea considerado ni igual, ni libre etc.

Afirmar que "existen" unos derechos humanos conlleva un doble expolio: a) dan a un hombre abstracto, que no existe, los atributos que no tiene el hombre concreto y b) se niega a la cruda realidad (de hombres sin derechos) capacidad de significación teórica. Construimos una teoría de derechos sobre el hombre que no tiene en cuenta al hombre real, sino a un hombre abstracto que se ha inventado la filosofía, pero que tiene el inconveniente de no existir.

Estas críticas a los derechos humanos no surgen, evidentemente, del poco aprecio por esa figura, sino del máximo reconocimiento de su significación. Los Derechos Humanos son la joya de la corona de la modernidad. Tomárselos en serio significa re-pensar el lugar en ellos de todos aquellos seres humanos que no tienen más capital que su dignidad de origen. Nunca ha sido este asunto menor (fue clave en el desencadenamiento de la II Guerra Mundial), pero ahora es urgente por la importancia de las migraciones en un mundo globalizado. Tengamos en cuenta que, en el pasado, la única respuesta a este problema fue el campo de concentración. "Si queremos impedir que se reabran ahora en Europa", dice Agamben, "los campos de exterminio", hay que repensar la figura del sujeto de los derechos humanos 0 , dicho de otra manera, la relación entre nacionalidad y ciudadanía, la relación entre el primero y el segundo artículo de la Déclaration des droits de l'homme et du citoyen de 1789. Hemos llegado a un punto en el que bien podemos aplicar al migrante lo que decía Arendt del refugiado: que son el paradigma de una nueva conciencia histórica, que representan la vanguardia de la humanidad.

\section{NOTAS}

Recibido: 15 de diciembre de 2008

Aceptado: 24 de marzo de 2009
1 Las referencias de Arendt están tomadas del apartado "Las perplejida- des de los Derechos del Hombre", en H. Arendt (1987): Los orígenes del totalitarismo, 2. Imperialismo, Alianza Editorial, Madrid, 422-438. 